\title{
Health seeking behavior and its determinants in Jaffna Sri Lanka
}

\author{
P. Kalki ${ }^{1,2}$, M. Thavorncharoensap ${ }^{2}$, A. Riewpaiboon ${ }^{2 *}$ \\ ${ }^{1}$ Unit of Allied health Sciences, Faculty of medicine, University of Jaffna, Sri Lanka. \\ ${ }^{2}$ Division of Social and Administrative Pharmacy, Department of Pharmacy, Faculty of \\ Pharmacy, Mahidol university, Thailand.
}

\begin{abstract}
Health seeking behaviour depends on trust in the health services and cost of services. Determinants of health seeking behavior include socio-economic status, culture, politic and current health. During the past decades, health seeking behavior has changed from traditional to western medicine and from public to private hospitals. Estimating this change is necessary for public health planning and resource allocation. The purpose of this study was to explore the health seeking behavior and its determinants in a Jaffna community in Northern Province of Sri Lanka. The study was an analytical cross-sectional survey conducted in Sri Lanka at household level. The data were collected through face-to-face interview using a questionnaire. Estimated sample size was 724 families, which were selected by multistage stratified cluster population proportionate random sampling method. Descriptive statistics was applied to summarize the variables. Inferential statistics was used to find the relationship between treatment type, institution type and socio demographic characters. Multivariate logistic regression was applied for determinants of health seeking behavior. Among the sample, 467 families or 863 participants were ill due to 5 selected diseases during the previous month, resulting in the incidence rates of illness 240 cases per 1000-person-month. The highest and lowest incidence was observed in cold plus flu (119 per 1000-person-month) and urinary tract problem (1 per 1000-person-month), respectively. Majority of the patients received institutional treatment $(55 \%)$ while self-medication was accounted for $45 \%$. Western medicine, traditional medicine, and the mix of both treatments were used by $65 \%, 11 \%$ and $24 \%$ of the patients respectively. Type of illness is a significant factor predicting health seeking behavior $(\mathrm{p}<0.001)$. Western style treatment at government hospital was the most common health seeking behavior among the patients in this study while important determinant was type of illness.
\end{abstract}

Keyword: health seeking behavior, determinants, community, Sri Lanka, self- medication

\section{INTRODUCTION}

Health seeking behaviour of society depends on both trust in the health services and cost of services. It has an influence on health service utilization and in turn the health outcomes of populations ${ }^{1}$. Dissatisfaction of services can be result from the poor staff attitude towards the patients which spoils the trust in the health services ${ }^{2}$. Gilson and several studies discussed about the decline of trust in health systems related to the relationship between health services and society ${ }^{2-5}$. Further, patient's factors that determine the health seeking behavior are culture, socio- economic status, politic or physical health ${ }^{1,6}$. Various studies described that individual's decision to choose health service was influenced by a variety of socio-economic factors; age, sex, social status of women, type of illness, access to services and perceived quality of the service?

Recently, there is a growing interest on health seeking behaviours and its determinants 
especially in the context of developing countries ${ }^{8}$. Similar to many developing countries, Sri Lanka's health system is in a situation of under-funding and shortage of skilled health man-power ${ }^{1}$. In addition, limited knowledge on illness and wellbeing, cost of services and cultural prescriptions were identified as barriers in health services utilization. These challenges are significant factors affect the health seeking behavior in Sri Lanka.

In many health care systems, private and public health sector may have conflict of interest. The private sector heeds to serve the opulence; consequently the public sector resources mainly serve for poor. There must be a dynamic cooperation between both public and private sector but private is rarely considered during health planning 9 . The private and public sector may substitute or complement for each other. Very often, public sector doctors establish their own private practice ${ }^{8}$. Trust in the service providers and service outlet features also play a major role in decision making about the choice of health facility ${ }^{8-11}$.

On the other hand, modernization has changed the health care utilization from traditional medicinal practice to western medicine due to the quick result and also to private hospitals. But recently they realized that traditional medicine have sound result with minimal side effects. Further, these choices of treatment affect the cost of treatment and cost of illness.

In 1982, traditional medicines form a central component in health care systems in developing countries where $80 \%$ of the population has been reported to depend on traditional medicine ${ }^{12-14}$. Later in 1997, Pouliot speculated that more than approximately $34 \%$ of the world's population may have been heavily reliant on medicinal plants ${ }^{12}$.

The Ayurveda and western style treatments are two major formally structured health system existence in Sri Lanka as in India ${ }^{15}$. Both are delivered absolutely free of charge at the point of delivery ${ }^{16}$. Due to high literacy rate and non-strict referral system of the country, the patient can bypass primary to secondary or tertiary care institutions with modern facilities ${ }^{17}$. Often, patients freely cross the provincial boundaries to full-fill their health care needs. As a result, major public health care institutions experience long waiting time, overcrowding and over-utilization in out-patient department and over $100 \%$ bed occupying rate in in-patient department ${ }^{18}$. Russell state that "high patient loads contribute to cursory consultations at state outpatient department facilities causing many patients to seek outpatient treatment at private clinics and pharmacies"19. Further, public sector doctors were legitimately allowed to practice in private setting since $1981^{20}$. As the result, private hospitals mushroomed in urban and rural township. Finally, patients' health seeking behavior is highly shared by private hospitals. In 2012, it was found that half of all outpatients visited were in the private hospital ${ }^{21}$.

A large number of health seeking behavior studies conducted in Sri Lanka are disease specific related to malaria and childhood disease $^{20,22-25}$. Studies on general health seeking behavior are limited. The purpose of the study was to explore the health seeking behavior of major illnesses and its determinants in a Jaffna community in Northern Province of Sri Lanka.

\section{MATERIALS AND METHODS}

The study was a cross-sectional survey analytical research. The five illnesses were selected for analysis which was cold plus flu, inflammatory problem, gastro intestinal problem, dermatological problem and urinary tract infection. Those are common illnesses of household in Sri Lanka ${ }^{15,26,27}$. Required sample size was calculated by using the formula: $n=Z^{2} \times P(1-P) / M^{2}$ $(\mathrm{n}=$ Sample size, $\mathrm{Z}=$ Standard Critical value for significance level which is 1.96 at $95 \%$ confidence level, $\mathrm{P}=$ estimated prevalence of health seeking behaviour in the study area, $\mathrm{M}=$ Margin of error $=1.5 \%$ ). With the absence of prevalence rates for the health seeking behaviour in similar setting, it was assumed to be $50 \%$ with a view to obtaining the highest possible sample size or to prevent underestimating of sample size calculation $^{28}$. According to the above formula and assumed value, the sample size was 1,068 participants. Researchers have planned to enroll 
2,136 participants to compensate for design effect. As the family size of the Jaffna district was 3.3 then 655 families had to be interviewed to full fill the 2136 participants ${ }^{29}$. Finally, 724 families were interviewed to compensate for the $10 \%$ non-respondent and incomplete reporting.

A family, which composed of at least 2 generations, was considered as a sample irrespective of legal or administrative category. Single headed families were excluded from the study. Each family member's health seeking behavior on selected illness information was retrieved from the respondent of the family. The respondent was a family member whose aged 18 or more, who made health decision or know the details of illness and treatment of all family members.

Multistage stratified cluster random sampling was employed. Fourteen divisional secretariat (DS) divisions were included in the study to better represent the district. One DS division, delft, was excluded from the study due to difficult to access the area and also low population size. From each DS, two Gramma nilathari divisions (GND) which is the lowest administrative area were randomly selected irrespective of population size and extent. Politically unstable, difficult to access and sensitive GND were excluded from random selection. Population proportionate random sampling method was used to determine the sample size of the selected GND. The household (family) list was obtained from Gramma Nilladari officer and assigned serial number. Each household was randomly selected from the list. In the case of inaccessibility (not available), a household nearby was selected.

Ethical clearance was obtained from Ethics Review Committee, Faculty of medicine, University of Jaffna, Sri Lanka and Institutional Review Board, Mahidol University, Thailand (Ref. No.: J/ERC/15/59/NDR/0111). Written informed consent was obtained from study participants prior to conducting the study and data were collected by face-to-face interview method using structured questionnaire. During the interview which was conducted between April to June 2015, the respondents were asked to recall about the health seeking behavior of selected 5 diseases for his/her family members in previous month ${ }^{23,30}$.

The SPSS version 21 was used to analyze the data. Descriptive statistics was applied to summarize variables. Mann-Whitney U Test and chi-square test statistic were used to explore the differences of patients' socio demographic characters, treatment type and type of institution. Multivariate logistic regression analysis was applied to analyze factors affecting health seeking behaviour.

Operational definitions in this study are the followings: Health Seeking Behaviour: The manner in which individuals monitor their bodies, define and interpret their symptoms, take remedial action, and utilize their sources of help, as well as engage with the more formal healthcare system ${ }^{31}$. For this study, the health seeking behaviour was based on the experience in the utilization of health facilities in Jaffna district in a month prior to an interview. Selfmedication (SM) category included those who had any medicinal drug for their illness without prescription and/or health-care professionals' advice, left-over medicine from others' prescription, refilling of expired prescription, obtained from kin and / or neighbors and leftover medicine of him/her from previous illness. Thus usage of over the counter drugs also accounted as selfmedication. The patients modify the prescribed drug while administering or obtained drug from a medical advice was not considered as selfmedication $^{32}$. Treatment Type: In this study there were six different types of health seeking behavior which were self-medication with western style, self-medication with traditional style, government hospital with western style, government hospital with traditional style, private hospital with western style, private hospital with traditional style. Single treatment was defined as: the situation when patient used only 1 treatment type from the above six treatment type. Combination of treatment was defined as: the situation when patient used more than one type of treatment.

\section{RESULT}

\subsection{Details of respondents}

Most respondents were female and 
their positions in family were spouse or chief occupant. Almost all respondent had at least primary education (98.7\%) with the mean age of 43(SD=13.6) years. Majority of them $(75 \%)$ have taken health care related decision in their family and they decided and influence their family members (Table 1).

The average family size of the participants was five ( $\mathrm{SD}=1.8)$ and no difference was observed between rural and urban area. The monthly average income of the respondent was Sri Lankan Rupee (LKR) 17,912 (SD 10,343), which was significantly higher in urban $(p=$ 0.029).

The patients' illness and demographic characteristics were summarized in Table 1. The mean age of patients were 30.1 (SD 22.4) years and ranged between 3 months to 92 years. Only $13(1.8 \%)$ of patients have never attended school. Most had at least primary education (98.2\%) and unemployed (34.7\%). Significant differences between rural and urban area were identified except for gender of patients, family size and type of illness as shown in Table 1. A total of 724 families were participated in the study which comprised 3,596 members and among 24\% were ill. Among them, 467 (65\%) families reported that their members were sick during a previous month. Specifically, a total of $863(37 \%)$ persons from the total of 2,343 participants in 467 household reported that he/she was sick from the selected 5 illnesses (Figure 1). An incidence of illness was presented in Table 2. The total incidence rate of illness of five diseases was 240 per 1000-person-month. The highest and lowest incidence were observed in cold plus flu (119 per 1000-person-month) and urinary tract problem (1 per 1000-person-month), respectively.

\subsection{Health seeking behavior}

Majority of patients, 471 [95\% CI (485, $457)]$ or $55 \%$ [95\% CI $(56.2,53.0)]$, preferred institutional treatment (non-self-medication or hospital), (Table 3). Among them, 285 (33\% [95\% CI $(34.6,31.5)])$ patients sought treatment from government hospitals, followed by private hospitals (160 or $19 \%$ of total, [95\% CI (19.8, 17.3)]) and mix of government- private hospitals
(26 or $3 \%$ of total, [95\% CI $(3.6,2.5)])$. As expected, high preference in institution was western style treatment (404 or $47 \%$ of total, [95\% CI $(48.4,45.2)])$, followed by traditional treatment (50 or $6 \%$ of total, [95\% CI (6.6, $5.0)]$ ). Almost all (88\%) of the patients who used government hospitals preferred western style treatment (Table 3).

Among the 392 (45\%, [95\% CI (47.1, 43.8)]) self-medicated patients, 124 (14\% of total, [95\% CI $(16.7,12.0)])$ were self-medication only (Table 3). Majority of self-medicated patients' preference were the mix of western-traditional medicine (190 or $22 \%$ of total), followed by western medicine (155 or $18 \%$ of total) and traditional medicine ( 47 or $5 \%$ of total). Western style treatment was solely preferred by 559 or $65 \%,[95 \%$ CI $(66.3,63.2)])$ patients. Likewise, traditional medicine was sought in 97 patients accounted for $11 \%$, [95\% CI $(12.3,10.2)]$ ) while the combination of western-traditional treatment was sought in 207 patients accounted for $24 \%$ [95\% CI $(25.4,22.6)])$. The use of western and traditional style of treatment were reported among 766 patients or $89 \%$, [95\% CI $(89.8,87.7)])$ and 304 patients or $35 \%,[95 \%$ CI $(36.2,33.7)])$, respectively. It includes the combination of western-traditional treatment. Of all treatment types reported in Table 3, first preference was western style treatment in government hospitals which was sought by $29 \%$ of the total patients.

\subsection{Health seeking behaviour in term of number of treatment type}

The sampled patients sought 30 types of treatment among 63 possible treatment choices (57 combination and 6 single types). Table 4 showed treatment type with type of illness. Significantly high number of patients (565 or $62 \%$ ) sought single than combination type of treatment $(p<0.001)$. Similar pattern was found across illness type. Double and three combination of treatment were utilized by 267 and 58 patients, respectively. Only 3 patients sought 4 types of treatment and only for cold plus fever. No patient utilized 5 and 6 treatment combination. In the single type of treatment, western style government hospital was the most preferred for each types of illness. 


\subsection{Determinants of self-medication}

Bivariate and multivariate Logistic regression model were employed to examine factors affecting self-medication. Urinary tract problem was excluded in logistic regression analysis due to small number $(\mathrm{n}=5)$. Age $(\mathrm{P}=$ $0.031)$ and type of illness $(\mathrm{P}<0.001)$ variable were significant predictors for self-medication in bivariate logistic regression (Table 5). Adult patients, those aged between 15 to 44 were $48 \%$ less likely to self-medicate than younger children [COR: $0.524 ; 95 \%$ CI: (0.349-0.788)]. Similar trend was observed patient age between 45 to 64 [COR: $0.571 ; 95 \%$ CI: (0.373-0.875)]. Table 6 shows that type of illness was the most significant predicting variable $(\mathrm{P}<0.001)$. The patients reported having inflammatory problem, were 55\% less likely than patients reported having cold plus flu to report self-medication [AOR: 0.451, 95\% CI: (0.310-0.654)]. Similarly, dermatological problem patients were also $75 \%$ less likely than cold plus flu patients to report self-medication. On the other hand, patients with gastro-intestinal problem showed similar self-medication practice with cold plus flu patients $(\mathrm{P}=0.612)$. Regarding age, even though the crude OR showed significance difference when adjusted to type of illness, it was no significant relationship between age and selfmedication.

\section{DISCUSSION}

Multistage stratified cluster population proportionate random sampling was conducted to attain the better representation of Jaffna district population. This method is suitable for unbiased estimation of samples variability ${ }^{33}$.

The proportion of ill person found in this current study was $24 \%$. It was lower than that of the national level, which found that nearly $31.7 \%$ of household population was ill during the previous month ${ }^{34}$. This may be due to the fact that government survey covered all the diseases while this current study covered only 5 diseases. Our study found that the ratio of people sought care at government $(36 \%)$ and private $(22 \%)$ hospital was $1.6: 1$. On the other hand, at national level, this ratio was $1: 1^{21}$.
This may be due to the poor access of private hospitals among the population in this region ${ }^{35}$. Further, the current study estimated only for one month which not accounted for seasonal variation. It also leads to different vales.

Most of the health care related decisions were taken by chief occupant of household (parents) and they decided and influence their family members. And this study found that self-medication was $45 \%$. Finding of this study was consistent with similar study conducted in Gamphaga and Polonnaruwa district, which found that self-medication was $34.6 \%{ }^{26}$. When looking at developing countries, prevalence of self-medication prevalence ranged between $12.7 \%$ to $95 \%{ }^{36,37}$ while for south-east Asia, it was widely practiced phenomenon with the prevalence of $50 \%$, reported in Indonesia ${ }^{38}$. In India, several studies found that self-medication was $71 \%{ }^{39}$. Interestingly, current study found that lower prevalence of self-medication compare to studies conducted in other countries. Wijesinge (2012) stated that "regularity of medical care and higher accessibility of health service reduce self-medication" 26 . In addition, various definitions on self-medication ${ }^{36}$ and included types of illness are also lead to different prevalence among countries and within the country.

The use of traditional treatment was found among $35 \%$ of the total patients. For patients reporting the use of traditional treatment, self-medication was common. Spiritual medicinal practice was not observed in this study. WHO mentioned that traditional medicine was widely practiced in Sri Lanka especially in rural area ${ }^{14}$. In the US, $56 \%$ of Indian who lived in America used Ayurveda in a previous month while $36 \%$ of the American used traditional medicine ${ }^{39}$.

When looking at the determinants of health seeking behavior, the crude OR showed significance difference with the age group. It was found that the middle age groups were less likely to self-medicated, as compared to the children aged under 5 . In a study, conducted in South Nigeria, middle agers group (25-45 years) had higher prevalence of self-medication than elders (over45) ${ }^{40}$ but other study showed that self-medicate was common in young age ${ }^{41}$. A study in Ragama, urban council of Sri Lanka, 
found that $85 \%$ of mothers self-medicated their children during the last three months ${ }^{24}$. So, in Sri Lanka higher prevalence of self-medication in children was not a new phenomenon.

In this study, gender was not a significant determinant of self-medication. This is similar to the study conducted in similar setting by Razana Faiz (2014) $)^{42}$. On the other hand, this study was inconsistent with other studies, which found that females was more likely to self-medicate ${ }^{26}$.

Unlike a study from Pakistan, this study found, no association between self- medication and education, employment and area $^{42}$. On the other hand, this study found that type of illness was the only one determinant factor for self- medication. This is similar to a study conducted in Pakistan, which found that selfmedication was common for pain, followed by respiratory problem, allergy, GIT problem and sleeping disturbances ${ }^{43}$. However, in our study, self-medication was most common for cold plus flu (respiratory problem), followed by GIT problem, inflammatory problem (pain) and dermatological problem. This is also similar to a study conducted in China, which revealed that self-medication and type of illness had significant association ${ }^{44}$.

After 1948, acquired independence from British, Sri Lanka delivers health care absolutely free of charge in addition to free education and food subsidy to whole of its population. The government policy promotes the government hospital utilization. The current result also consistent with state policy that majority of the patients' preference were government hospital treatment. The rich peoples' preference was private hospital due to the reduction in long waiting time and cursory consultations. The policy makers have to consider for this phenomenon and strengthening the smaller institutions to avoid overcrowding.

\section{Limitation}

Generalization of study result should be made with caution as the study includes only one district. In addition, only 5 illnesses were included in the study and were identified using self-reported. In addition, some patients could not differentiate between the private hospital western and traditional treatment. The appearance and way of practicing of private hospital may mislead the patient's judgments.

\section{Recommendations for further study}

The maximum benefit for the determinants of health seeking behavior should be obtained through the combination of qualitative methods. The geographical area should be extended to five district of Northern Province. Furthermore, the self-reported disease should be replaced by the definite diagnose disease.

\section{CONCLUSION}

Among the reported illness cold plus flu were higher prevalence. Single type of treatment which was western style at government hospital was the most parent decision at institutional level. The majority of self-medication was the combination between western and traditional treatment. Even though, age was significant predictor for self-medication but after adjusting for other factors, there was no significant relationship. Only, type of illness was significant determinant of health seeking behavior. Majority of the population practiced self-medication for gastro intestinal problem and cold plus flu.

The policy makers should be considering the high prevalence of self-medication and strengthening the community pharmacy to prevent the misuse of drugs and enhance the safe self-medication. The policy makers should be aware of the potential for increase in the public health service utilization in Jaffna especially in rural areas.

\section{REFERENCES}

1. Musoke D, Boynton P, Butler C, Musoke MB. Health seeking behaviour and challenges in utilising health facilities in Wakiso district, Uganda. Afr Health Sci. 2014; 14(4):1046-55.

2. Gilson L. Trust and the development of health care as a social institution. Soc Sci Med. 2003;56(7):1453-68. 
3. Birungi $H$. Injections and self-help: risk and trust in Ugandan health care. Soc Sci Med. 1998;47(10):1455-62.

4. Davies H. Falling public trust in health services: implications for accountability. J Health Serv Res Policy. 1999;4(4):193-4.

5. Mechanic D. The managed care backlash: perceptions and rhetoric in health care policy and the potential for health care reform. Milbank Q. 2001;79 (1):35-54; 2 p preceding VI.

6. Kroeger A. Anthropological and sociomedical health care research in developing countries. Soc Sci Med. 1983;17(3):147-61.

7. Tipping G, Segall M. Health care seeking behaviour in developing countries: an annotated bibliography and literature review. Development Bibliography, 12. Brighton, UK: Institute of Development Studies, University of Sussex. 1995.

8. Shaikh BT, Hatcher J. Health seeking behaviour and health service utilization in Pakistan: challenging the policy makers. J Public Health. 2005; 27(1):49-54.

9. Hanson K, Berman P. Private health care provision in developing countries: a preliminary analysis of levels and composition. Health Policy Plan. 1998;13(3): 195-211.

10. Newman RD, Gloyd S, Nyangezi JM, Machobo F, Muiser J. Satisfaction with outpatient health care services in Manica Province, Mozambique. Health Policy Plan. 1998;13(2):174-80.

11. Sadiq H, Muynck AD. Health care seeking behavior of pulmonary tuberculosis patients visiting TB Center Rawalpindi. JPMA J Pak Med Assoc. 2001;51(1):10-6.

12. Pouliot M. Relying on nature's pharmacy in rural Burkina Faso: empirical evidence of the determinants of traditional medicine consumption. Soc Sci Med. 2011;73(10): 1498-507.

13. Njoroge GN, Kaibui IM, Njenga PK, Odhiambo PO. Utilisation of priority traditional medicinal plants and local people's knowledge on their conservation status in arid lands of Kenya (Mwingi
District). J Ethnobiol Ethnomed. 2010; 6:22.

14. World Health Organization. Legal Status of Traditional Medicine and Complementary/ Alternative Medicine: SA Worldwide Review Geneva: WHO; 2001 [cited 2015 Sep 12]. Available from: http://apps.who.int/medicinedocs/pdf/h2943e/h2943e.pdf.

15. Waxler-Morrison NE. Plural medicine in Sri Lanka: do Ayurvedic and Western medical practices differ? Soc Sci Med. 1988;27(5):531-44.

16. Ministry of Health Nutrition and Indigenous Medicine. Annual health bulletin 2014. Ministry of Health, Nutrition and Indigenous Medicine, Colombo, Sri Lanka: Medical Statistics Unit; 2016.

17. Mendis UA, Beneragama BVSH, Jayalath KD, Chinta A, editors. Mannual on management on drugs. 3rd ed: Ministry of Health Care \& Nutrition; 2008.

18. IPS. Strategies for improving the health of the poor: the Sri Lankan experience. Colombo, Sri Lanka: Department of International Development, UK, by the Institute of Policy Studies, 2011.

19. Russell S. Treatment-seeking behaviour in urban Sri Lanka: trusting the state, trusting private providers. Soc Sci Med. 2005;61(7): 1396-407.

20. Amarasiri de Silva MW, Wijekoon A, Hornik R, Martines J. Care seeking in Sri Lanka: one possible explanation for low childhood mortality. Soc Sci Med. 2001; 53(10):1363-72.

21. Amarasinghe S, Alwis SD, ShanazSaleem, Rannan-Eliya RP, Dalpatadu S. Private Health Sector Review 2012. IHP Technical Reports Series Number 2 [Internet]. 2015 Aug 21. Available from: http://www.ihp.lk/ publications/docs/PHSR2012.pdf.

22. Kirkby K, Galappaththy GN, Kurinczuk JJ, Rajapakse S, Fernando SD. Knowledge, attitudes and practices relevant to malaria elimination amongst resettled populations in a post-conflict district of northern Sri Lanka.Trans Royal Soc Trop Med Hyg. 2013;107(2):110-8. 
23. Attanayake N, Fox-Rushby J, Mills A. Household costs of 'malaria' morbidity: a study in Matale district, Sri Lanka. Trop Med Int Health. 2000;5(9):595-606.

24. S H Kariyawasam, D N Nanayakkara, M A C P Mohottiarachchi, Y L S Nandasena. A descriptive cross sectional study on mothers self-medicating children. Sri lanka J Child Health. 2005;34:7-12.

25. Konradsen F, Amerasinghe PH, Perera D, Van der Hoek W, Amerasinghe FP. A village treatment center for malaria: community response in Sri Lanka. Soc Sci Med. 2000; 50(6):879-89.

26. Wijesinghe PR, Jayakody RL, Seneviratne RdA. Prevalence and predictors of selfmedication in a selected urban and rural district of Sri Lanka. WHO South East Asia J Public Health. 2012;1(1):14.

27. Raal A, Volmer D, Soukand R, Hratkevits S, Kalle R. Complementary treatment of the common cold and flu with medicinal plantsresults from two samples of pharmacy customers in Estonia. PloS One. 2013;8 (3):e58642.

28. Perera J, Kirthinanda DS, Wijeratne S, Wickramarachchi TK. Descriptive cross sectional study on prevalence, perceptions, predisposing factors and health seeking behaviour of women with stress urinary incontinence. BMC Womens Health. 2014; 14:78.

29. Government Agent. Population report of jaffna district. In: census and statistics, editor. Jaffna, Sri Lanka: District Secretarit Jaffna; 2014.

30. Attanayake N. The Economic cost of five common diseases in Sri Lanka asthma, hypertension, ischaemic heart disease, diarrhoea and viral fever - study report 2. Sri Lanka, Colombo: Ministry of Healthcare and Nutrition; 2005. 35 p.

31. Anwar M, Green J, Norris P. Health-seeking behaviour in Pakistan: a narrative review of the existing literature. Public Health. 2012;126(6):507-17.

32. Weerasinghe MC, Fernando DN. Paradox in treatment seeking: an experience from rural Sri Lanka. Qual Health Res. 2011;21(3): 365-72.
33. Horvitz DG, Thompson DJ. A generalization of sampling without replacement from a finite universe. J Am Stat Assoc. 1952;47 (260):663-85.

34. Department of Census and Statistics-Srilanka. Household Income and Expenditure Survey - 2012/13 2013 [cited 2014 Apr 14]. Available from: http://www.statistics.gov. $1 \mathrm{k} /$ page.asp?page $=$ Income $\% 20$ and $\% 20$ Expenditure.

35. Nagai M, Abraham S, Okamoto M, Kita E, Aoyama A. Reconstruction of health service systems in the post-conflict Northern Province in Sri Lanka. Health Policy. 2007;83(1):84-93.

36. Figueiras A, Caamano F, Gestal-Otero JJ. Sociodemographic factors related to selfmedication in Spain. Eur J Public Health. 2000;16(1):19-26.

37. Kasilo OJ, Nhachi CF, Mutangadura EF. Epidemiology of household medications in urban Gweru and Harare. Cent Afr J Med. 1991;37(6):167-71.

38. World Health Organization. Self-care in the Context of Primary Health 2009 [cited 2015 Oct 03]. Available from: http://www. searo.who.int/entity/primary_health_care/ documents/sea_hsd_320.pdf.

39. Satow YE, Kumar PD, Burke A, Inciardi JF. Exploring the prevalence of Ayurveda use among Asian Indians. J Alter Complement Med. 2008;14(10):1249-53.

40. Osemene KP, Lamikanra A. A Study of the Prevalence of Self-Medication Practice among University Students in Southwestern Niger. Trop J Pharm Res. 2012;11(4):689.

41. Sharma R, Verma U, Sharma C, Kapoor B. Self-medication among urban population of Jammu city. Indian J Pharmacol. 2005;37 (1):40-3.

42. Razana Faiz. Health seeking Behaviour: A perspective from Male, Maldives [Thematic Paper]. Bangkok: Mahidol University; 2014.

43. T Aqeel, A Shabbir, H Basharat, M Bukhari, S Mobin, H Shahid, et al. Prevalence of Self-Medication among Urban and Rural Population of Islamabad, Pakistan. Trop J Pharm Res. 2014;14(3):7.

44. Li Y, Rao K, Ren X. Use of and factors associated with self-treatment in China. BMC Public Health. 2012;12. 